\title{
The use of hazardous sludge solidification and green-lipped mussel shells in cementitious material: a case study of ngcc power plant of priok
}

\author{
Samuel Dwima Halim ${ }^{1, *}$,Edbert Rainer ${ }^{1}$, Chris Ryantonius ${ }^{1}$, Bagas $_{\text {Panandito }}{ }^{1}$, Doni Wardoyo $^{1}$, Mhd Reza Fahlevy $^{1}$, and \\ Ivan Sandi Darma ${ }^{2}$ \\ ${ }^{1}$ Civil Engineering Division, Faculty of Civil and Environmental Engineering, Bandung Institute of Technology, Indonesia \\ ${ }^{2}$ Structural Engineering Division, Faculty of Civil and Environmental Engineering, Bandung Institute of Technology, Indonesia
}

\begin{abstract}
This paper aims to introduce the utilization of hazardous sludge with green-lipped mussel shells as concrete mixture components. The hazardous sludge is a side product of wastewater treatment plant operated in NGCC Priok, while green-lipped mussel shells are side product of community activity in Kalibaru, North Jakarta, Indonesia. Utilization is dedicated to preserve the environment, reducing both hazardous sludge generations from wastewater treatment plant and potential waste from social activities in the coastal area. Three different groups of concretes were prepared. The first group contains normal concretes with W/C ratio of 0.5 . Subsequently, the second group contains concretes with dry sludge and mussel as a replacement of fine aggregate at different contents, $5 \%(\mathrm{C} 1), 10 \%(\mathrm{C} 2)$, and $15 \%(\mathrm{C} 3)$, with $\mathrm{W} / \mathrm{C}$ ratio of 0.5 . Finally, the last group contains concretes with dry sludge as cement replacement and the green-lipped mussel as fine aggregate replacement at different contents of 5\% (C4), 10\% (C5), and 15\% (C6). The results show that dry sludge and green-lipped mussel provide better results when used as a substitute for fine aggregate rather than as cement replacement. In addition, the rate of strength development of concretes containing waste additions are slow compared to normal concretes.
\end{abstract}

\section{Introduction}

Sewage sludge production from waste water treatment plants are increasing all over the world. This kind of sludge includes the solid material left from sewage treatment processes. Generally, sludge still has high enough water content, therefore it is necessary to treat sludge which is part of the wastewater treatment. The percentage of water content can reach $95-99 \%$. The main purpose of sludge treatment is to reduce the volume of sludge by separating water from the sludge before disposal, in order to facilitate the transport process. Therefore, the reduction of water content and sludge volume is important.

However, it should be noted that sludge may cause more harmful environmental disturbances than wastewater by considering that sludge contains more concentrated pollutants and may contain new types of contaminants that are not contained previously in the wastewater resulting from the addition of chemicals and from the decomposition of the compounds contained in the sludge. In this regard, waste treatment measures are required from the planning stage so that steps and strategies can be prepared to address negative impacts on the environment and bring about positive impacts. Sometimes, waste still has value and can be used as raw materials or other useful materials.
Furthermore, pollutants not only come from sludge but also many other waste materials that can be a source of pollutants. One of them is shell waste. For this waste, shells need a container to place, manage and develop its potential to not only be a mere waste, but to be something useful and profitable in addition to reducing the waste of the shell itself.

Many studies have been conducted to determine how far we can optimize the use of waste, especially in the field of construction materials. Valls et.al [1] confirmed that up to $10 \%$ of treatment plant sludge can be added to concrete for use in certain very specific applications. Meanwhile, by applying dry sludge as a replacement of fine aggregate, Jamshidi et.al [2] proposed as non-constructional concrete such as paving and flooring. The use of higher volume of dry and wet sludge in concrete as a replacement of cement content has been explored by Rabie [3].

However, the common thread that can be drawn from those studies is a decrease in the strength of concrete. Recent investigations show that the partial replacement of cement by sewage sludge ash led to substantial retardation of hydration rates [4]. The next problem that would arise is how much the mechanical properties of the concrete will decrease if two types of waste are used as a mixture of concrete.

\footnotetext{
* Corresponding author: sam.dwima@gmail.com
} 
In this paper, we explored the effect of the concretes containing two types of waste addition i.e. dry sludge and green-lipped mussel shells. With the proposed mixture proportions coupled with various curing periods, the behavior of multiple addition of waste materials in concrete mixture would be further understood.

\section{Materials and method}

\subsection{Sewage sludge and green-lipped mussel}

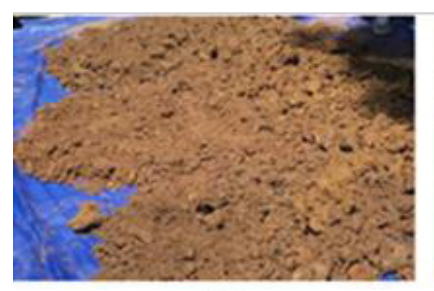

(a)

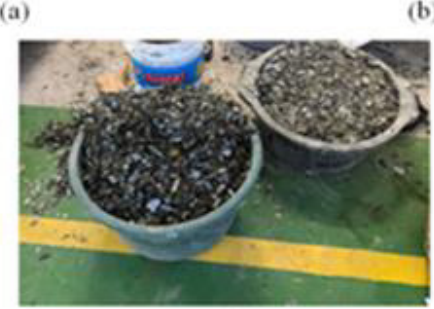

(c)

Fig. 1. Waste Addition (a). Raw sewage sludge. (b) Oven dried sludge. (c) Green-lipped mussel

Figure 1 shows the waste addition used in this research. The sludge and green-lipped mussel were prepared by PT. Indonesia Power UPJP Tanjung Priok. The sludge was then oven dried for 24 hour with the temperature of $105^{\circ} \mathrm{C}$. Furthermore, the sludge was grinded and sifted out in the sieve with the size of $2.36 \mathrm{~mm}$ (Figure 1(b)). As for the green-lipped mussel, pounding process was applied in order to reduce the size of the mussel. The maximum size of mussel used in the concrete mixture is around $15 \mathrm{~mm}$ (Figure 1(c)).

\subsection{Mix proportion and curing}

Table 1. Mixture composition

\begin{tabular}{ccccccc}
\hline Mixture & $\begin{array}{c}\text { Cement } \\
\text { (kg) }\end{array}$ & $\begin{array}{c}\text { Water } \\
\text { (kg) }\end{array}$ & $\begin{array}{c}\text { Grave } \\
\text { (kg) }\end{array}$ & $\begin{array}{c}\text { Sand } \\
(\mathbf{k g})\end{array}$ & $\begin{array}{c}\text { Sludge } \\
(\mathbf{k g})\end{array}$ & $\begin{array}{c}\text { Misse } \\
(\mathbf{k g})\end{array}$ \\
\hline C0 & 450 & 225 & 915 & 610 & 0 & 0 \\
C1 & 450 & 225 & 915 & 549 & 30.5 & 30.5 \\
C2 & 450 & 225 & 915 & 488 & 61 & 61 \\
C3 & 450 & 225 & 915 & 427 & 91.5 & 91.5 \\
C4 & 427.5 & 225 & 915 & 579.5 & 22.5 & 30.5 \\
C5 & 405 & 225 & 915 & 549 & 45 & 61 \\
C6 & 382.5 & 225 & 915 & 518.5 & 67.5 & 91.5 \\
\hline
\end{tabular}

In order to study the effects of treated dry sludge and green-lipped mussel on concrete, mix designs with water to cement ratios of 0.5 was prepared. In this research, mixture compositions can be classified into three different groups as shown in Table 1. First composition contains normal concretes as a control specimen $(\mathrm{C} 0)$.
The next group contains concretes with waste addition (dry sludge and mussel) as a replacement of fine aggregate at different contents of $5 \%(\mathrm{C} 1), 10 \%(\mathrm{C} 2)$ and $15 \%(\mathrm{C} 3)$. Finally, the last group contains concretes with dry sludge used for secondary binder (cement replacement) and the green-lipped mussel used as fine aggregate replacement at different contents of 5\% (C4), $10 \%(\mathrm{C} 5)$ and $15 \%(\mathrm{C} 6)$. In addition, to increase the rate of solidification of the concretes due to the use of sludge, water-based cement admixture (ECO5000) was utilized. Furthermore, after casting, all specimens were left for a day in molds in humid condition at laboratory condition. Then they were removed and immersed in water for 6 , 13 and 27 days.

\section{Results and discussion}

\subsection{Compressive strength evolution with the increasing curing periods}

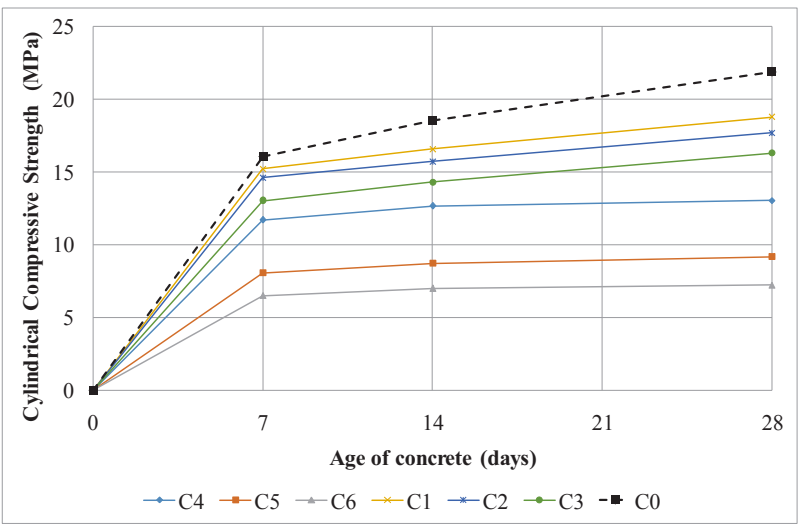

Fig. 2. Evolution of compressive strength of concrete

Figure 2 shows the evolution of compressive strength of concretes. As shown in the Figure 2, the resistance to compression of samples are always increasing with the increasing curing periods. However, it can be seen that the use of higher amount of waste additions as fine aggregate replacement resulting in the reduction of compressive strength of concrete having the same amount of cement content at the same curing period. Meanwhile, the compressive strength of the samples in which dry sludge used for secondary binder (cement replacement) and the green-lipped mussel used as fine aggregate replacement show the lowest as compared with that of normal as well as the concretes containing waste additions as fine aggregate replacement.

Sludge may form a coating on aggregate particles, resulting in weakened bond between the aggregate and the mortar. Excessive amounts of these fine materials may also unduly increase the water demand of the concrete, resulting in loss of concrete strength and an increase in its permeability. Subsequently, it can be worsened by reducing of cement content in the mixture. 


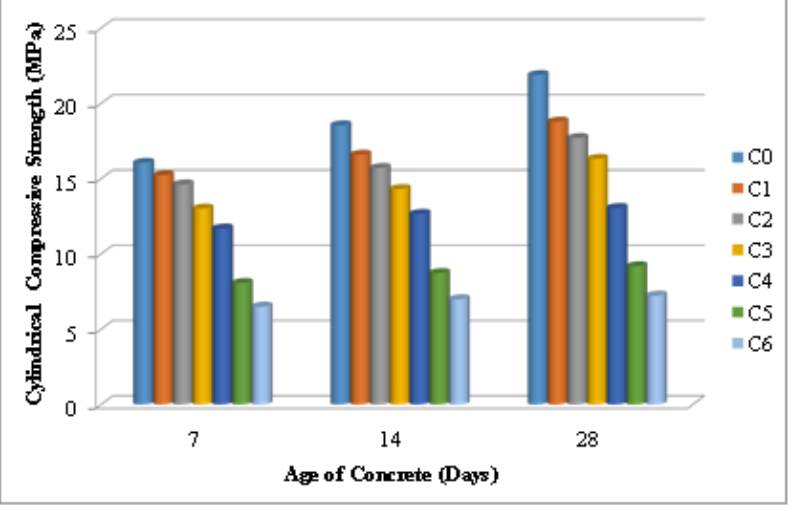

Fig. 3. Comparison of compressive strength at 7, 14, and 28 days

Figure 3 shows the comparison of strength at 7, 14 and 28 days. From Figure 3, it can be seen that the usage of waste additions of $5 \%, 10 \%$, and $15 \%$, as fine aggregate replacement is reducing the compressive strength of concrete at 28 days up to $14.1 \%, 19.1 \%$ and $25.4 \%$, respectively. As for samples in which sewage sludge used for secondary binder (cement replacement) and the green-lipped mussel used as fine aggregate replacement, the compressive strength in 28 days reduce significantly up to $40.3 \%, 58.0 \%$ and $66.9 \%$ for $5 \%, 10 \%$, and $15 \%$ replacement, respectively.

\subsection{Rate of strength development with the increasing of waste materials content}

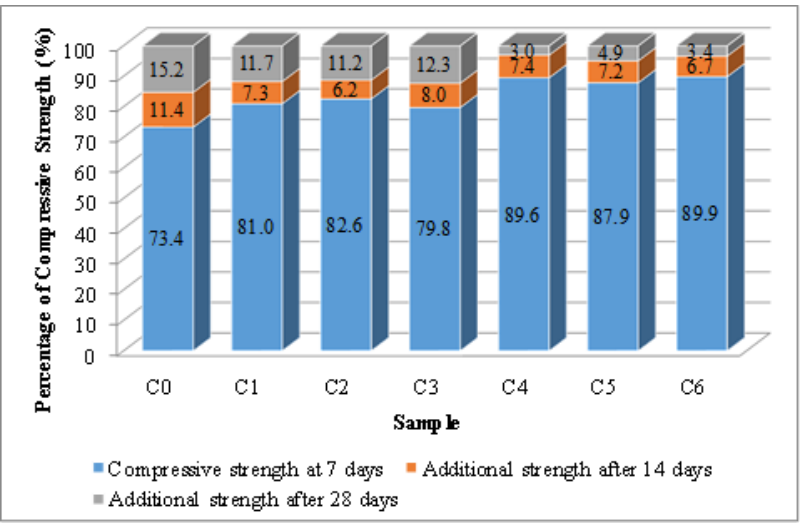

Fig. 4. Concrete strength development rate

The rate of concrete strength development of each samples are shown in the Figure 4. As shown in the Figure 4, the rate of development of waste additions concretes in 7 days curing periods are comparable to the normal concretes. It was $73.4 \%$ for normal concretes (C0). Meanwhile, for the samples of $\mathrm{C} 1, \mathrm{C} 2$ and $\mathrm{C} 3$, the rate of development varies from $79.8 \%$ to $82.6 \%$. As for samples in which sewage sludge used for secondary binder (cement replacement) and the green-lipped mussel used as fine aggregate replacement (C4, C5 and C6) those rate varies from $87.9 \%$ to $89.9 \%$.

Furthermore, as the hydration reaction continues, the strength of the concrete increases. The additional strength of concrete after 14 days curing periods as compared with that of 28 days of $\mathrm{C} 0$ is $11.4 \%$. For the group of samples using waste additions in the concrete mixture, the additional strength that can be achieved are similarly vary from $6.2 \%$ to $8.0 \%$.

Moreover, from 14 days to 28 days, there is still additional strength of concrete due to the amount of unhydrated cement grain undergone hydration reaction. However the amount of additional strength is vary for each group of sample. The group of samples in which sewage sludge used for secondary binder (cement replacement) and the green-lipped mussel used as fine aggregate replacement ( $\mathrm{C} 4, \mathrm{C} 5$ and $\mathrm{C} 6)$ were recorded to have the smallest increase in the strength during 14 to 28 days curing periods.

The rate of strength development of group samples $\mathrm{C} 1, \mathrm{C} 2$, and $\mathrm{C} 3$ makes them almost reaches the same compressive strength of the normal mixture, especially until day 14. This could be attributed to a minor pozzolanic effect as reported by other authors [5]. Meanwhile, as for the other samples of C4, C5, and C6, the reduction of cement content and low pozzolanic activity are causing the waste additions act as filler or particle packing in the microstructure of concrete. However, sludge itself has a tendency to coat the aggregate rather than fill the gap presence in the mortar. Therefore, the function of the sludge as filler might not be achieved.

\section{Conclusion}

In this research, the use of multiple waste materials in the concrete mixture has been presented while several new findings were also provided. There is still a potential for concrete containing multiple waste materials to be used as structural and constructional element. The used of multiple waste materials as fine aggregate provided better performance as compared with that of cement replacement. However, the rate of strength development of concretes containing waste materials should be of concern. Time required from initial setting to day 7 becomes crucial periods for concrete containing waste materials in developing its strength. After 7 days, the rate of strength development significantly decrease.

\section{Acknowledgement}

This research was fully supported by PT. Indonesia Power UPJP Tanjung Priok (162.SPK/061/TGP/17). The first author also express gratitude for the facilities support from Structure Engineering Laboratory, Bandung Institute of Technology.

\section{References}

1. S. Valls, A. Yague, E. Vazquez, C. Mariscal, Cem. Conc. Res., 34, 2203- 2208, (2004)

2. A. Jamshidi, N. Mehrdadi, M. Jamshidi, J. Envi. Stud., Vol. 37, No. 59, (2011)

3. Rabie, J Civil Environ Eng, 6, 209, (2016) 
4. N. Rodriguez, S. Ramirez, M. Blanco Varela, M. Guillem, J. Puig, E. Larrotcha, J. Flores, Cem. Conc. Res., 40, 778-786, (2010)

5. M. Cyr, P. Coutand, P. Clastres, Cem. Conc. Res., 37, 1278-1289, (2007). 